\title{
Oncogenic Wnt3a: a promising specific biomarker in hepatocellular carcinoma
}

\author{
Min Yao, 2,\#, Miao Fang ${ }^{1, \#, ~ W e n-J i e ~ Z h e n g ~}{ }^{1}$, Deng-Fu Yao' \\ 'Research Center of Clinical Medicine, Affiliated Hospital of Nantong University, Nantong 226001, Jiangsu, China. \\ 2Department of Immunology, Medical School of Nantong University, Nantong 226001, Jiangsu, China. \\ \#Authors contributed equally.
}

Correspondence to: Prof. Deng-Fu Yao, Research Center of Clinical Medicine, Affiliated Hospital of Nantong University, Nantong 226001, Jiangsu, China. E-mail: yaodf@ahnmc.com

\begin{abstract}
How to cite this article: Yao M, Fang M, Zheng WJ, Yao DF. Oncogenic Wnt3a: a promising specific biomarker in hepatocellular carcinoma. Hepatoma Res 2018;4:30. http://dx.doi.org/10.20517/2394-5079.2018.32
\end{abstract}

Received: 28 Mar 2018 First Decision: 22 May 2018 Revised: 11 Jun 2018 Accepted: 11 Jun 2018 Published: 6 Jul 2018

Science Editor: Guang-Wen Cao Copy Editor: Jun-Yao Li Production Editor: Cai-Hong Wang

\begin{abstract}
Hepatocellular carcinoma (HCC) is still one of the most common and rapidly fatal malignancies worldwide with a multi-factorial, multi-step, complex process, and poor prognosis. Early discovery and effective therapy of HCC are of utmost importance. Recent studies demonstrated that Wnt/ $\beta$-catenin pathway play important roles in occurrence and development of HCC including hepatocytes malignant transformation, metastasis, chemoresistance and liver cancer stem cells. Oncogenic wingless-type MMTV integration site family member 3a (Wnt3a) signaling is a promising biomarker in diagnosis and prognosis for HCC. This review presents current data on mechanisms of hepatocarcinogenesis involving participation of the Wnt canonical pathway, and focuses on the Wnt3a expression in HCC progression and its clinical application.
\end{abstract}

Keywords: Hepatocellular carcinoma, Wnt/ $\beta$-catenin pathway, signal molecules

\section{INTRODUCTION}

Hepatocellular carcinoma (HCC) is one of the most common or deathly human malignancy cancers worldwide ${ }^{[1,2]}$, especially in the areas along the Yangtze River. Recently, Chen et al ${ }^{[3]}$ reported the observed survival and relative survival of leading cancer sites from a population-based cancer registry for 40 years. The main sites of the cancer types with a total of 92,780 incident cases in Qidong, China, HCC ranks the first based on the rank order of incidence among all malignancies (liver, stomach, lung, colon and rectum, oesophagus, breast, pancreas, leukaemia, brain and central nervous system, bladder, non-Hodgkin's 
Table 1. Chromosomal location of Wnt genes and tissue distribution

\begin{tabular}{|c|c|c|c|}
\hline Gene & Location & $\begin{array}{c}\text { Accession } \\
\text { numbers }\end{array}$ & Tissues or tumors \\
\hline Wnt $7^{[22]}$ & $12 \mathrm{q} 13$ & X03072 & Lipomas, myxoid liposarcomas, pleomorphic adenomas, myomas \\
\hline Wnt $2^{[23]}$ & $7 q 31$ & X07876 & Lung, heart \\
\hline Wnt $2 b / 13^{[24]}$ & $1 \mathrm{p} 13$ & $\begin{array}{l}\text { XM052111, } \\
\text { XM052112 }\end{array}$ & Cervical cancer, gastric cancer \\
\hline Wnt $3^{[25]}$ & $17 q 21$ & AY009397 & Breast \\
\hline Wnt $3 a^{[26]}$ & $1 \mathrm{q} 42.13$ & AB060284 & Spinal cord, brain, liver \\
\hline Wnt $4^{[27]}$ & 1 1p35 & AY009398 & Breast \\
\hline Wnt $5 a^{[28]}$ & 3p14-p21 & L20861 & Neonatal heart, lung, liver \\
\hline Wnt $5 b^{[29]}$ & $12 \mathrm{p} 13.3$ & AB060966 & Prostate, fetal brain \& lung, kidney, liver, ovary, small intestine \\
\hline Wnt $6^{[30]}$ & $2 q 35$ & AY009401 & Kidney, placenta, spleen \\
\hline Wnt $7 a^{[31]}$ & $3 p 25$ & D83175 & Placenta, kidney, testis, uterus, fetal lung, brain \\
\hline Wnt $7 b^{[32]}$ & $22 q 13.3$ & AB062766 & Brain, kidney, prostate, lung, esophageal, gastric, pancreatic cancer \\
\hline Wnt $8 a / d^{[33]}$ & $5 q 31$ & $\begin{array}{l}\text { AB057725, } \\
\text { AY009402 }\end{array}$ & Teratocarcinoma, mesoderm \\
\hline Wnt $8 b^{[34]}$ & $10 q 24$ & Y11094 & Forebrain \\
\hline Wnt $10 a^{[30]}$ & $2 q 35$ & AB059569 & Kidney, placenta, spleen, brain, liver \\
\hline Wnt $10 b / 12^{[35]}$ & $12 q 13.1$ & U81787 & Lung, uterus, thymus, spleen, breast \\
\hline Wnt $77^{[36]}$ & $11 q 13.5$ & Y12692 & Skeleton, lung \\
\hline Wnt $14^{[37]}$ & $1 q 42$ & AB060283 & Breast \\
\hline Wnt $15^{[37]}$ & $17 q 21$ & AF028703 & Breast \\
\hline Wnt $16^{[38]}$ & $7 q 31$ & $\begin{array}{l}\text { XM031374, } \\
\text { XM00488 }\end{array}$ & Spleen, appendix, lymph nodes \\
\hline
\end{tabular}

lymphoma, and cervix) and the poorest survival rate ${ }^{[3]}$. The leading etiological factors of HCC include chronic hepatitis $\mathrm{B}$ or $\mathrm{C}$ virus $\left(\mathrm{HBV}^{[4-6]}\right.$ or $\left.\mathrm{HCV}^{[7,8]}\right)$ infection, aflatoxin contaminated food taken and non-alcohol fat liver diseases (NAFLD $)^{[9,10]}$. Chronic HBV carriers have a 5-15-fold increased risk of HCC compared with the general population. HBV-related proteins are known to take control of several cellular pathways like Wnt/ $\beta$ catenin, TGF- $\beta$, Raf/MAPK, and ROS for the virus's own replication ${ }^{[11-13]}$.

Carcinogenesis of HCC is a multi-factor, multi-step and complex process. Most of HCC patients died quickly because of the rapid tumor progression, and hepatic resection or transplantation is the only potential curative treatment for HCC patients ${ }^{[1,15]}$. Activation of the Wnt/ $\beta$-catenin signaling pathway plays a significant role in the pathology and physiology of the liver and has been identified as a main factor in HCC because of hepatocytes malignant transformation with numerous genetic/epigenetic abnormalities, and affects cellular persistence, multiplication, migration, alteration and genomic instability ${ }^{[16-18]}$. Abnormal expressions of Wnt signaling molecules were closely associated with the occurrence and progression of HCC. Recently, Pan et al. ${ }^{[1,20]}$ discovered and reported that the overexpression of oncogenic winglesstype MMTV integration site family member 3a (Wnt3a) could be a specific biomarker in diagnosis and prognosis of HCC. However, its exact underlying mechanisms in hepatocarcinogenesis still remain poorly understood. This review presents new advances of the underlying mechanisms of Wnt signaling, and focuses on expressions of hepatic or circulating Wnt3a, which serve as a promising molecular biomarker for HCC.

\section{REGULATING MECHANISMS OF Wnt SIGNALINGS}

Human Wnt genes encode a large family of secreted proteins that have been reported in many tissues ${ }^{[21]}$. Total 19 Wnt proteins in human tissues or cancers are shown in Table 1. Proteins were identified that share $27 \%$ to $83 \%$ amino acid sequence identity, and evolutionarily conserved glycoproteins with 23 or 24 cysteine residues. Human Wnt proteins are all very similar in size, ranging in molecular weight from $39 \mathrm{kDa}$ (Wnt7a) to $46 \mathrm{kDa}$ (Wnt10a). Wnt protein folding may depend on the formation of multiple intramolecular disulfide 
bonds. Analysis of the signaling activities of chimeric Wnt proteins has shown that the carboxy-terminal region of Wnt proteins may play a role in determining the specificity of responses to different Wnts. The amino-terminal region may mediate interactions with Wnt receptors but requires the carboxyl terminus to activate these receptors. The main regulating mechanisms of Wnt signaling are either through canonical pathway (Wnt1, Wnt2, Wnt3, Wnt3a, Wnt8a, Wnt8b, Wnt10a, and Wnt10b) characterized by the stabilization and subsequent nuclear transport of $\beta$-catenin resulting in the activation of transcriptional responses or via non-canonical pathway (Wnt4, Wnt5a, Wnt5b, Wnt6, Wnt7a, Wnt7b, and Wnt11) with more diverse and several different signaling modes that regulate cell biological behaviors ${ }^{[22-38]}$.

The Wnt signaling molecules have been involved in liver tumorigenesis with activating liver cancer stem cells ${ }^{[39]}$. In adults, Wnts function in homeostasis, and inappropriate activation of the Wnt pathway is implicated in a variety of cancers. Some signaling molecules in the Wnt pathway have been recognized to play an important role in the development and progression of tumors and regulate multiple cellular events such as cell proliferation, differentiation, and apoptosis through $\beta$-catenin-dependent canonical- or $\beta$-catenin-independent noncanonical pathway ${ }^{[40]}$. Abnormal expression of some key molecules in the Wnt/ $\beta$ catenin pathway was associated with the development and progression of HCC. Wnt3a gene located on chromosome (1q42.13) has been regarded as an activator inducing $\beta$-catenin accumulation and activating the canonical Wnt signaling pathway. Studies on human Wnt3a have focused primarily on its key role in liver malignancy, and its high expression in cancerous tissues has been confirmed with a worse outcome ${ }^{[20]}$.

\section{HBV INVOLVED IN Wnt ACTIVATION}

HBV has a global distribution and is one of the leading causes of HCC. Its viral replication with several pathways like Wnt/ $\beta$-catenin, TGF- $\beta$, Raf/MAPK and ROS affects cellular persistence, multiplication, migration, alteration and genomic instability ${ }^{[1,42]}$. The Wnt/FZD/ $\beta$-catenin pathway associated with HBVrelated HCC development because of the progression of chronic liver diseases is known to be accompanied by disturbances in $\beta$-catenin expression (mainly overexpression) ${ }^{[43,44]}$, with its cytoplasmic or nuclear translocation. Viral proteins of HBV ( $\mathrm{HBx}$ and HBsAg) can act as pathogenic factors that are involved in the modulation and induction of canonical Wnt signaling activation with aberration of adenomatous polyposis coli (APC), AXIN, secreted Frizzled related protein (SFRP) 1 and SFRP5.

The canonical Wnt signals are transduced through Frizzled receptors and LRP5/LRP6 co-receptors located on the cell membrane, initiating the $\beta$-catenin signaling cascade ${ }^{[45,46]}$. This multi-protein destruction complex could target the proto-oncogene $\beta$-catenin for ubiquitin-mediated proteolysis, prevent glycogen syntheses kinase 3â (GSK-3â)-mediated $\beta$-catenin degradation, leading to nuclear translocation of $\beta$-catenin, combine with T-cell factor/lymphoid enhancer factor, and thereby promote the transcription of downstream target genes, including FGF20, DKK1, WISP1, MYC, CCND1, and so on. Their interaction results in the enhancement of the pathway and leads to hepatocarcinogenesis ${ }^{[47,48]}$. Thus, lack of Wnt secretion from hepatocytes did not affect overall injury, fibrosis or HCC burden although there were protein expression differences in tumor conformation $^{[49]}$.

\section{HCV PROVOKED Wnt SIGNALING}

Epidemiological studies have validated the association between HCV infection and HCC. An increasing number of studies show that protein-protein interactions between HCV proteins and host proteins play a vital role in infection and mediate HCC progression ${ }^{[50]}$. The role of nonstructural (NS5A) protein of HCV in vivo has been accentuated in induction of this pathway mainly to the canonical pathway. Interaction of Wnt signaling with HCV genome in hepatocarcinogenesis linked $\beta$-catenin phosphorylation and abnormalities in the E-cadherin-catenin unit function lead to loss of intercellular junctions, progression in liver fibrosis, and development of cirrhosis and $\mathrm{HCC}^{[51,52]}$. Accumulating evidence indicates that HCV core or nonstructural 
proteins provoke activation of the Wnt/ $\beta$-catenin signaling pathway, and the evidence supporting a role of $\mathrm{Wnt} / \beta$-catenin signaling in the onset and progression of HCC is compelling ${ }^{[33,54]}$.

Progression of HCV-related liver diseases is noted to be accompanied by disturbances in $\beta$-catenin overexpression, with its cytoplasmic or nuclear translocation and with lower expression of E-cadherin. More $\beta$-catenin mutations are manifested in HCV-associated than in HBV-related HCC. HCV proteins affect in a double manner expression of E-cadherin, including modulation of the Wnt pathway and reduction of E-cadherin expression at the transcriptional level. Alterations in cellular locations of $\beta$-catenin and E-cadherin in chronic HCV and HCC pointed to structural disturbances in intercellular junctions in livers and presence of the transcriptionally inactive form of $\beta$-catenin ${ }^{[5,56]}$. Promoter hypermethylation of Wnt inhibitors was discovered in HCV-induced multistep hepatocarcinogenesis ${ }^{[57]}$, and the reduced expression of E-cadherin in long-lasting chronic HCV might represent an early indicator of the epithelial-mesenchymal transition $^{[58,55]}$.

\section{COUNTERACTIVE Wnt3a WITH Wnt5a IN HCC}

Although accumulating clinical and basic evidences have suggested that the Wnt signaling is associated with the HCC progression ${ }^{[60]}$. However, little research has been reported on the relationship between Wnt3a and HCC. Previous studies have found that Wnt3a showed higher expression in HCC than liver tissues, positively correlated with its target genes MMP 7 and c Myc. Intriguingly, their expressions are significantly correlated with Notch3 and Hes1 expression. Wnt3a was highly expressed in MHcc97H and SK Hep 1 cells in vitro ${ }^{[61]}$, as an important regulator of human HCC cell line growth, which could induce activation of the canonical Wnt pathway after binding with SULF2 and GPC-3. Also, it could increase cell proliferation in nude mouse xenografts in vivo ${ }^{[0,61]}$.

The expressions of hepatic Wnt3a were investigated in HCC tissues [Figure 1]. The positive Wnt3a with brown staining particles was mainly distributed in cytosol and membrane of hepatocytes in cancerous tissues and no or lower expression in their surrounding tissues. High Wnt3a expression like its down-stream disheveled 2, DKK1, and SFRP1 were all identified as independent predictive factors for poor HCC outcome ${ }^{[20,62-64]}$. Compared with high hepatic Wnt3a in HCC tissues, the significant difference of Wnt5a intensity was found between low level in HCC tissues and high expression in their para-cancerous tissues. The intensity of Wnt5a expression was inversely correlated with Wnt3a level in cancerous tissues. Both decreasing Wnt5a and increasing Wnt3a expression in HCC tissues relation to the clinical staging from stage I to IV were confirmed as independent prognosis factors of HCC patients. The Kaplan-Meier survival curves demonstrated that HCC patients with high Wnt3a expression had a significantly lower survival rate compared to cases with lower Wnt3a [Figure 2], Wnt3a expression was associated with poorly-differentiated grade, liver cirrhosis, chronic HBV infection, and higher TNM stage, indicating that the abnormal Wnt3a expression could participate in promoting hepatocytes malignant transformation and progression of $\mathrm{HCC}^{[65,66]}$.

\section{SERUM Wnt3a FOR HCC SPECIFIC DIAGNOSIS}

Early diagnosis of HCC is of the utmost importance. Successful screening for HCC at early stage is challenging due to the lack of well characterized and specific biomarkers ${ }^{[67,68]}$. Data of previous studies have confirmed that some Wnt signalings could modify HCC growth and invasive ability. However, achieving successful screening of abnormal Wnt3a signaling is critically important as early diagnosis could potentially provide an early monitoring opportunity. Along these lines, the Wnt pathway has been identified as contributing to the development and progression of HCC. Although serological AFP marker is commonly applied to HCC diagnosis, it has exhibited a low sensitivity and specificity with approximately $40 \%$ of negative patients. Although many biomarkers have been applied in diagnosis for HCC, only a few markers were confirmed with higher specificity or sensitivity for HCC, especially in early stage or small size HCC ${ }^{[69-71]}$. 


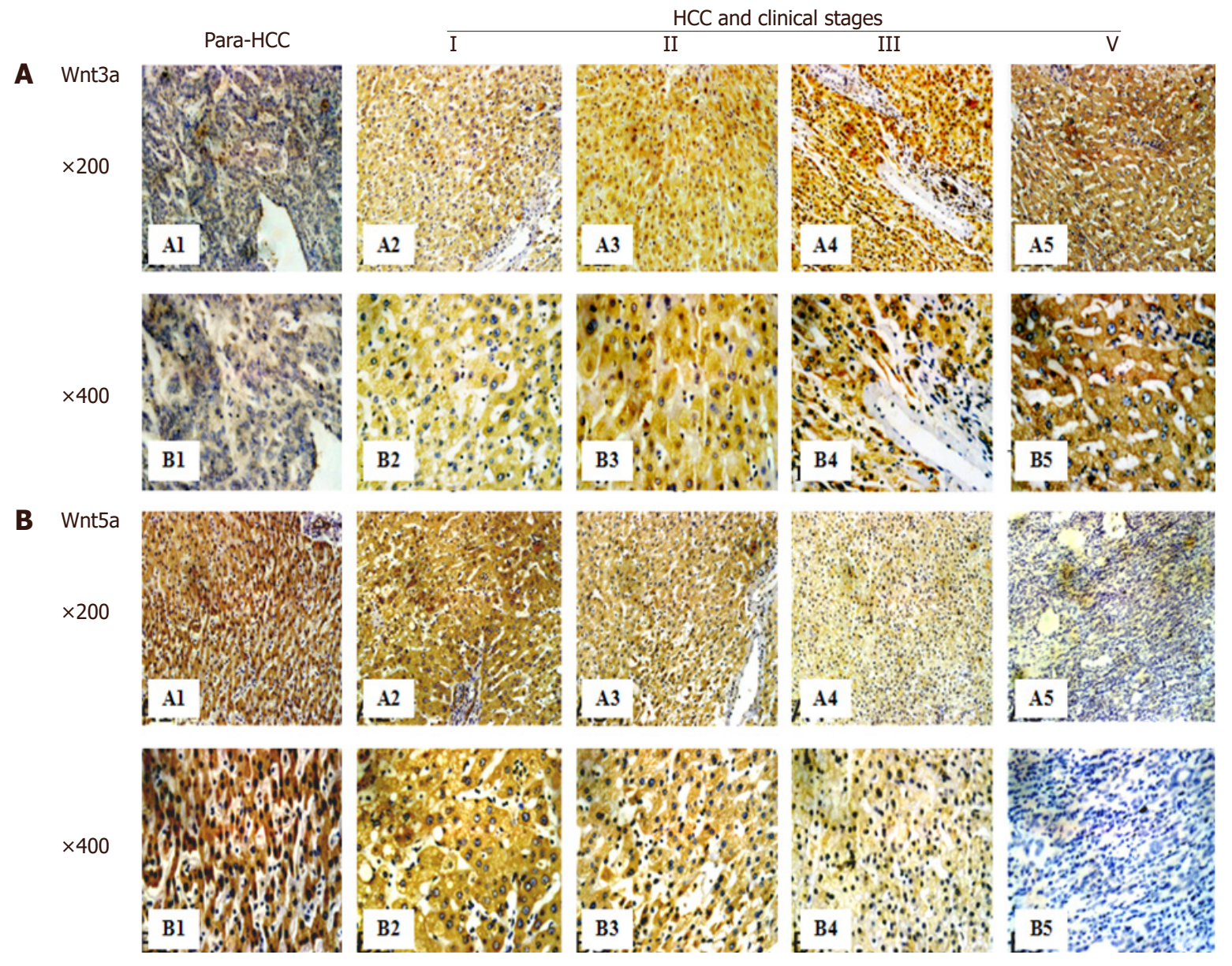

Figure 1. Immunohistochemistry of Wnt3a or Wnt5a expression in HCC tissues with different staging ${ }^{[20,65]}$. (A) The Wnt3a expression in HCC tissues (SP, original magnification: A1-A5, $\times 200$; B1-B5, $\times 400$ ); (B) the Wnt5a expression in HCC tissue (SP, original magnification, $A 1-A 5, \times 200 ; B 1-B 5, \times 400)$. In Wnt3a, A1 and B1, the low or without Wnt3a expression in the para-cancerous tissues, and A2-A5 and B2-B5, the brown staining of Wat3a expression with gradually increasing from stage I, II to III-IV of HCC tissues; In Wnt5a, A1 and B1, the strongest Wnt3a expression in the para-cancerous tissues, and A2-A4 and B2-B4, the brown staining of Wat3a expression with gradually decreasing from stage I to III of HCC tissues, and A5 and B5, the low or without Wnt5a expression were discovered in HCC tissues at stage IV. HCC: hepatocellular carcinoma tissues; Para-HCC: paracancerous tissues; Wnt3a: wingless-type MMTV integration site family member 3a; Wnt5a: wingless-type MMTV integration site family member 5a

Cancerous Wnt3a was over-expressed and could secrete into circulating blood. The incidence of serum Wnt3a level (> $800 \mathrm{ng} / \mathrm{L}$ ) in HCC patients was $92.5 \%$ with significantly related to AFP level, liver cirrhosis, HBV infection, low differentiation degree, TNM staging, and extra-hepatic metastasis ${ }^{[19]}$. According to the diagnostic specificity or the area under the receiver operating characteristic (ROC) curve, serological Wnt3a detection has been confirmed superior to AFP, HS-GGT ${ }^{[72]}$, and GPC- $3^{[73]}$ with higher sensitivity and lower false-positive rate for HBV-related HCC patients [Table 2]. The combining of serum Wnt3a plus AFP detection has complemented diagnostic value and raised the sensitivity up to $96.3 \%$ for HCC diagnosis which was obviously higher in Wnt3a or AFP alone for distinguishing malignancy from benign liver lesions, suggesting that serum Wnt3a should be a novel specific marker for HCC diagnosis that was superior to routine AFP detection $^{[74]}$ according to the specificity and the area under the ROC curve, especially in diagnosis of AFPnegative HCC.

\section{Wnt3a SIGNALING WITH HCC TARGETED-THERAPY}

Once HCC is advanced, there are multiple therapeutic venues, but most eventually fail. Effective treatment of HCC still is a challenging problem worldwide. Therefore, developing novel molecule-targeted therapies may 

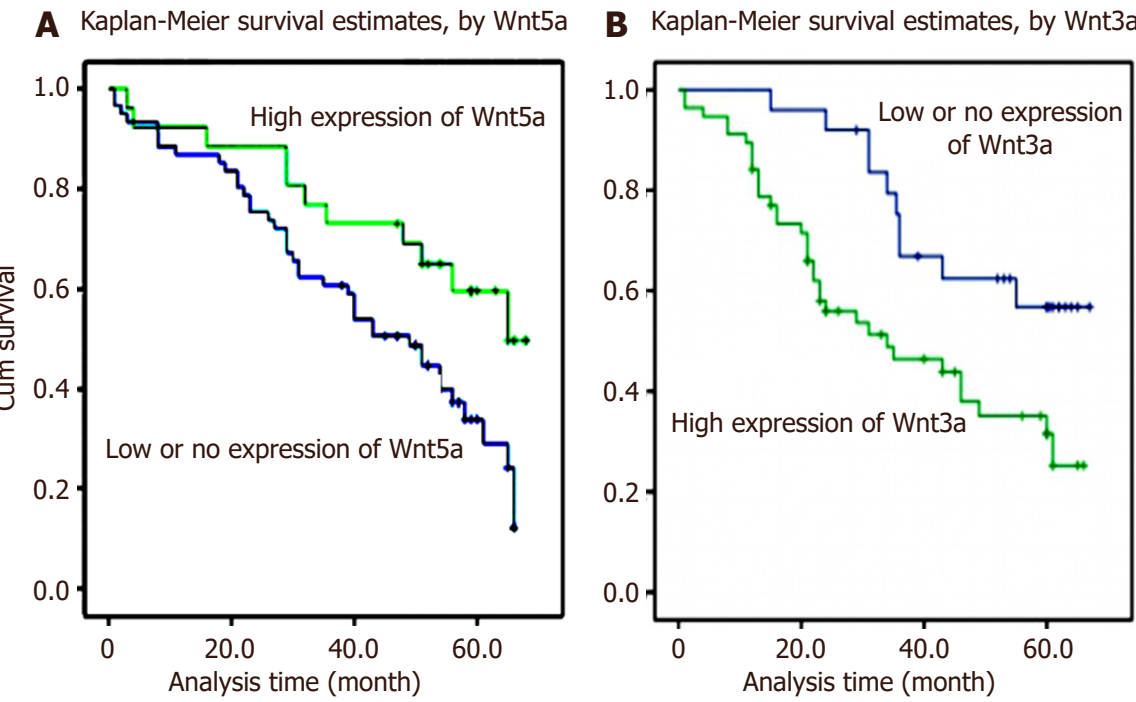

Figure 2. Overall survival curves of Wnt5a or Wnt3a expression in $\mathrm{HCC}^{[20,65]}$. The hepatic Wnt5a or Wnt3a expression curves were calculated according to the Kaplan-Meier method. The accumulative survival curves of patients with HCC were made according to HCC tissues with low or high expression for Wnt5a or Wnt3a level (log-rank test, $P<0.001$ ). (A) Wnt5a in HCC; (B) Wnt3a in HCC. HCC: hepatocellular carcinoma; Wnt3a: wingless-type MMTV integration site family member 3a; Wnt5a: wingless-type MMTV integration site family member $5 a$

Table 2. Comparative analysis of circulating Wnt3a, AFP, HS-GGT, and GPC-3 detection in diagnosis of HCC

\begin{tabular}{|c|c|c|c|c|c|}
\hline & $\begin{array}{c}\text { Wnt3a } a^{[19]} \\
(>800 \mathrm{ng} / \mathrm{L})\end{array}$ & $\begin{array}{c}\text { AFP }^{[19]} \\
(>50 \mathrm{ng} / \mathrm{mL})\end{array}$ & $\begin{array}{l}\text { HS-GGT }^{[17]} \\
(>5.5 \mathrm{U} / \mathrm{L})\end{array}$ & $\begin{array}{l}\text { GPC- }^{[67]} \\
\text { (positive) }\end{array}$ & $\begin{array}{c}\text { Wnt3a }{ }^{[19]} \\
+ \text { AFP }\end{array}$ \\
\hline Sensitivity (\%) & 92.50 & 61.25 & 85.70 & 52.84 & 96.25 \\
\hline Specificity (\%) & 94.34 & 69.81 & 97.24 & 99.58 & 62.26 \\
\hline Accuracy (\%) & 93.23 & 64.66 & 96.20 & 83.57 & 82.71 \\
\hline PPV (\%) & 96.10 & 75.38 & 89.70 & 98.48 & 79.38 \\
\hline NPV (\%) & 89.29 & 54.41 & 92.23 & 80.20 & 91.67 \\
\hline
\end{tabular}

Wnt3a + AFP: combining detection of serum Wnt3a and AFP concentration; Wnt3a $(n=80)$, AFP $(n=80)$, HS-GGT $(n=91)$, and GPC-3 ( $n=123$ ). PPV: positive predictive value; NPV: negative predictive value; HCC: hepatocellular carcinoma; GPC-3: glypican-3; HSGGT: HCC-specific gamma-glutamyl transferase; AFP: alpha fetoprotein

provide greater chance for effective therapies ${ }^{[75]}$ or overcoming resistance to sorafenib ${ }^{[76]}$. Many mechanisms have been involved in the aberrant activation of Wnt signaling and regulating $\beta$-catenin activity ${ }^{[77]}$ or function by using small molecules (LGK974 ${ }^{[78]}$, Celecoxib ${ }^{[79]}$, Genistein ${ }^{[80]}$ ), specific antibodies (OMP-54F28, OTSA101) ${ }^{[8]]}$ and small size peptide SAH-BCL- ${ }^{[82]}$. However, only a few of anti-cancer drugs that have been developed to target the related pathway of HCC formation or development have entered into pre-clinical trials, and none of these have advanced to the late clinical trial stage.

Oncogenic Wnt3a is involved in HCC development and increasing Wnt3a plays a crucial role in cell proliferation and metastasis, particularly in progression and mediated-oncogenesis involving signaling pathways, with brown granule-like staining localized in cancerous parts of atypical hyperplasia ${ }^{[1,20]}$. Targeted oncogenic glypican-3 gene transcription of Wnt upstream inhibited the proliferation of human hepatoma cells by specific short hairpin $\mathrm{RNA}^{[83]}$. Down-regulating Wnt3a expression inhibited cell viability and induced Go/G1 cell cycle arrest via decreased expression of cyclin D1 and c Myc, and increased expression of p21 and p27. In addition, deletion of Wnt3a significantly inhibited migration and invasion by down-regulating MMP 2/-7/-9 expression via the MAPK (p38, ERK1/2 and JNK) pathway ${ }^{[61]}$. The abnormality of liver and circulating Wnt3a expression in HCC has provided initial evidence, and suggested that targeted-Wnt3a signaling could be a promising target or an effective target for HCC therapy. 


\section{PERSPECTIVES}

In conclusion, molecular factors are involved in the process of HCC development and metastasis. $\mathrm{HBx}$ could integrate into human genome and this transcript could activate Wnt signaling as a long noncoding $\mathrm{RNA}^{[84]}$. The associations between Wnt signaling and cancer initiation, tumor growth, metastasis, dormancy, immunity and tumor stem cell maintenance have been revealed, and Wnt signaling has exhibited numerous genetic abnormalities ${ }^{[85,86]}$ as well as epigenetic alterations including modulation of DNA methylation. The overexpression of Wnt3a in cancerous tissues has been discovered, and its higher level was only found in sera of HCC patients from a cohort study in chronic liver diseases, although it is the first time to report as a novel specific marker for HCC diagnosis and prognosis. Further studies will permit us to analyze Wnt3a role in hepatocarcinogenesis and explore its molecular-targeted for HCC therapy ${ }^{[87,88]}$.

\section{DECLARATIONS}

\section{Authors' contributions}

Conception and literature search: Yao M, Zheng WJ

Drafting the manuscript: Yao M, Fang M

Critical revision for intellectual content: Yao DF

\section{Availability of data and materials}

Not applicable.

\section{Financial support and sponsorship}

This work was supported by the grants from the Projects of National Natural Science Foundation of China (81673241, 81702419), Jiangsu Medical Programs (KYCX17_ 1934, BE2016698), and Int. S\&T Cooperation Program (2013DFA32150) of China.

\section{Conflicts of interest}

All authors declare that there are no conflicts of interest.

\section{Ethical approval and consent to participate}

Not applicable.

\section{Consent for publication}

Not applicable.

\section{Copyright}

(c) The Author(s) 2018.

\section{REFERENCES}

1. Finn RS, Zhu AX, Farah W, Almasri J, Zaiem F, Prokop LJ, Murad MH, Mohammed K. Therapies for advanced stage hepatocellular carcinoma with macrovascular invasion or metastatic disease: a systematic review and meta-analysis. Hepatology 2018;67:422-35.

2. Fujiwara N, Friedman SL, Goossens N, Hoshida Y. Risk factors and prevention of hepatocellular carcinoma in the era of precision medicine. J Hepatol 2018;68:526-49.

3. Chen JG, Zhu J, Zhang YH, Zhang YX, Yao DF, Chen YS, Lu JH, Ding LL, Chen HZ, Zhu CY, Yang LP, Zhu YR, Qiang FL. Cancer survival in Qidong between 1972 and 2011: a population-based analysis. Mol Clin Oncol 2017;6:944-54.

4. Yang F, Ma LT, Cao GW. Hepatocellular carcinoma: co-evolution of hepatocytes and hepatitis B virus. Zhonghua Gan Zang Bing Za Zhi 2017;25:321-4. (in Chinese)

5. Tong Hv, Bock CT, Velavan TP. Genetic insights on host and hepatitis B virus in liver diseases. Mutat Res Rev Mutat Res 2014;762:65-75.

6. Du Y, Han X, Ding YB, Yin JH, Cao GW. Prediction and prophylaxis of hepatocellular carcinoma occurrence and postoperative recurrence in chronic hepatitis B virus-infected subjects. World J Gastroenterol 2016;22:6565-72.

7. Matsuura K, Tanaka Y. Host genetic variations associated with disease progression in chronic hepatitis C virus infection. Hepatol Res 
2018;48:127-33.

8. Chen LP, Zhao J, Du Y, Han YF, Su T, Zhang HW, Cao GW. Antiviral treatment to prevent chronic hepatitis B or C-related hepatocellular carcinoma. World J Virol 2012;1:174-83.

9. Seto WK, Yuen MF. Nonalcoholic fatty liver disease in Asia: emerging perspectives. J Gastroenterol 2017;52:164-74.

10. Margini C, Dufour JF. The story of HCC in NAFLD: from epidemiology, across pathogenesis, to prevention and treatment. Liver Int 2016;36:317-24.

11. Han YF, Zhao J, Ma LY, Yin JH, Chang WJ, Zhang HW, Cao GW. Factors predicting occurrence and prognosis of hepatitis-B-virus-related hepatocellular carcinoma. World J Gastroenterol 2011;17:4258-70.

12. Cao GW. Clinical relevance and public health significance of hepatitis B virus genomic variations. World J Gastroenterol 2009;15:5761-9.

13. Pan L, Yao M, Yao D. Clinical significance of abnormal Wnt signaling pathway expression in hepatitis and hepatocellular carcinoma. Zhonghua Gan Zang Bing Za Zhi 2015;23:797-800. (in Chinese)

14. Rinninella E, Cerrito L, Spinelli I, Cintoni M, Mele MC, Pompili M, Gasbarrini A. Chemotherapy for hepatocellular carcinoma: current evidence and future perspectives. J Clin Transl Hepatol 2017;5:235-48.

15. Zhan T, Rindtorff N, Boutros M. Wnt signaling in cancer. Oncogene 2017;36:1461-73.

16. Noda T, Nagano H, Takemasa I, Yoshioka S, Murakami M, Wada H, Kobayashi S, Marubashi S, Takeda Y, Dono K, Umeshita K, Matsuura N, Matsubara K, Doki Y, Mori M, Monden M.. Activation of Wnt/beta-catenin signalling pathway induces chemoresistance to interferon-alpha/5-fluorouracil combination therapy for hepatocellular carcinoma. Br J Cancer 2009;100:1647-58.

17. Yao DF, Huang ZW, Chen SZ, Huang JF, Lu JX, Xiao MB, Meng XY. Diagnosis of hepatocellular carcinoma by quantitative detection of hepatoma-specific bands of serum gamma-glutamyltransferase. Am J Clin Pathol 1998;110:743-9.

18. Yao M, Yao DF, Bian YZ, Zhang CG, Qiu LW, Wu W, Sai WL, Yang JL, Zhang HJ. Oncofetal antigen glypican-3 as a promising early diagnostic marker for hepatocellular carcinoma. Hepatobiliary Pancreat Dis Int 2011;10:289-94.

19. Pan LH, Yao M, Zheng WJ, Gu JJ, Yang XL, Qiu LW, Cai Y, Wu W, Yao DF. Abnormality of Wnt3a expression as novel specific biomarker for diagnosis and differentiation of hepatocellular carcinoma. Tumour Biol 2016;37:5561-8.

20. Pan LH, Yao M, Cai Y, Gu JJ, Yang XL, Wang L, Yao DF. Oncogenic Wnt3a expression as an estimable prognostic marker for hepatocellular carcinoma. World J Gastroenterol 2016;22:3829-37.

21. Miller JR. The Wnts. Genome Biol 2002;3:3001.

22. Arheden K, Mandahl N, Strombeck B, Isaksson M, Mitelman F. Chromosome localization of the human oncogene INT1 to 12q13 by in situ hybridization. Cytogenet Cell Genet 1988;3:86-7.

23. McMahon JA, McMahon AP. Nucleotide sequence, chromosomal localization and developmental expression of the mouse int-1-related gene. Development 1989;3:643-50.

24. Katoh M, Hirai M, Sugimura T, Terada M. Cloning, expression and chromosomal localization of Wnt-13, a novel member of the Wnt gene family. Oncogene 1996;3:873-6.

25. Roelink H, Wang J, Black DM, Solomon E, Nusse R. Molecular cloning and chromosomal localization to 17q21 of the human WNT3 gene. Genomics 1993;3:790-2.

26. Roelink H, Nusse R. Expression of two members of the Wnt family during mouse development-restricted temporal and spatial patterns in the developing neural tube. Genes Dev 1991;3:381-8.

27. Huguet EL, McMahon JA, McMahon AP, Bicknell R, Harris AL. Differential expression of human Wnt genes 2, 3, 4, and 7B in human breast cell lines and normal and disease states of human breast tissue. Cancer Res 1994;3:2615-21.

28. Geng M, Cao YC, Chen YJ, Jiang H, Bi LQ, Liu XH. Loss of Wnt5a and Ror2 protein in hepato- cellular carcinoma associated with poor prognosis. World J Gastroenterol 2012;18:1328-38.

29. Saitoh T, Katoh M. Molecular cloning and characterization of human WNT5B on chromosome 12p13.3 region. Int J Oncol 2001;3:347-51.

30. Kirikoshi H, Sekihara H, Katoh M. WNT10A and WNT6, clustered in human chromosome 2q35 region with head-to-tail manner, are strongly coexpressed in SW480 cells. Biochem Biophys Res Commun 2001;3:798-805.

31. Ikegawa S, Kumano Y, Okui K, Fujiwara T, Takahashi E, Nakamura Y. Isolation, characterization and chromosomal assignment of the human WNT7A gene. Cytogenet Cell Genet 1996;3:149-52.

32. Kirikoshi H, Sekihara H, Katoh M. Molecular cloning and characterization of human WNT7B. Int J Oncol 2001;3:779-83.

33. Saitoh T, Katoh M. Molecular cloning and characterization of human WNT8A. Int J Oncol 2001;3:123-27.

34. Lako M, Lindsay S, Bullen P, Wilson DI, Robson SC, Strachan T. A novel mammalian wnt gene, WNT8B, shows brain-restricted expression in early development, with sharply delimited expression boundaries in the developing fore-brain. Hum Mol Genet 1998;3:813-22.

35. Bui TD, Rankin J, Smith K, Huguet EL, Ruben S, Strachan T, Harris AL, Lindsay S. A novel human Wnt gene, WNT10B, maps to 12q13 and is expressed in human breast carcinomas. Oncogene 1997;3:1249-53.

36. Lako M, Strachan T, Bullen P, Wilson DI, Robson SC, Lindsay S. Isolation, characterisation and embryonic expression of WNT11, a gene which maps to $11 \mathrm{q} 13.5$ and has possible roles in the development of skeleton, kidney and lung. Gene 1998;3:101-10.

37. Bergstein I, Eisenberg LM, Bhalerao J, Jenkins NA, Copeland NG, Osborne MP, Bowcock AM, Brown AM. Isolation of two novel WNT genes, WNT14 and WNT15, one of which (WNT15) is closely linked to WNT3 on human chromosome 17q21. Genomics 1997;3:450-8.

38. Fear MW, Kelsell DP, Spurr NK, Barnes MR. Wnt-16a, a novel Wnt-16 isoform, which shows differential expression in adult human tissues. Biochem Biophys Res Commun 2000;3:814-20.

39. Wang R, Sun Q, Wang P, Liu M, Xiong S, Luo J, Huang H, Du Q, Geller DA, Cheng B. Notch and Wnt/ß-catenin signaling pathway play important roles in activating liver cancer stem cells. Oncotarget 2016;7:5754-68. 
40. Mokkapati S, Niopek K, Huang L, Cunniff KJ, Ruteshouser EC, deCaestecker M, Finegold MJ, Huff V. $\beta$-Catenin activation in a novel liver progenitor cell type is sufficient to cause hepatocellular carcinoma and hepatoblastoma. Cancer Res 2014;74:4515-25.

41. Guerrieri F, Belloni L, Pediconi N, Levrero M. Molecular mechanisms of HBV-associated hepatocarcinogenesis. Semin Liver Dis 2013;33:147-56.

42. Daud M, Rana MA, Husnain T, Ijaz B. Modulation of Wnt signaling pathway by hepatitis B virus. Arch Virol 2017;162:2937-47.

43. Monga SP. $\beta$-Catenin signaling and roles in liver homeostasis, injury, and tumorigenesis. Gastroenterology 2015;148:1294-310.

44. Park S, Lim J, Kim JR, Cho S. Inhibitory effects of resveratrol on hepatitis B virus X protein-induced hepatocellular carcinoma. J Vet Sci 2017;18:419-29.

45. Yen CJ, Ai YL, Tsai HW, Chan SH, Yen CS, Cheng KH, Lee YP, Kao CW, Wang YC, Chen YL, Lin CH, Liu T, Tsai HP, Wang JR, Su IJ, Huang W. Hepatitis B virus surface gene pre-S2 mutant as a high-risk serum marker for hepatoma recurrence after curative hepatic resection. Hepatology 2018; doi: 10.1002/hep.29790.

46. Gao Y, Feng J, Yang G, Zhang S, Liu Y, Bu Y, Sun M, Zhao M, Chen F, Zhang W, Ye L, Zhang X. Hepatitis B virus X protein-elevated MSL2 modulates hepatitis B virus covalently closed circular DNA by inducing degradation of APOBEC3B to enhance hepatocarcinogenesis. Hepatology 2017;66:1413-29.

47. Geng M, Xin X, Bi LQ, Zhou LT, Liu XH. Molecular mechanism of hepatitis B virus X protein function in hepatocarcinogenesis. World J Gastroenterol 2015;21:10732-8.

48. Ashmawy AM, Elgeshy KM, Abdel Salam ET, Ghareeb M, Kobaisi MH, Amin HAA, Sharawy SK, Abdel Wahab AHA. Crosstalk between liver-related microRNAs and Wnt/ $\beta$-catenin pathway in hepatocellular carcinoma patients. Arab J Gastroenterol 2017;18:144-50.

49. Preziosi M, Poddar M, Singh S, Monga SP. Hepatocyte Wnts are dispensable during diethylnitrosamine and carbon tetrachloride-induced injury and hepatocellular cancer. Gene Expr 2018; doi: 10.3727/105221618X15205148413587.

50. Han Y, Niu J, Wang D, Li Y. Hepatitis C virus protein interaction network analysis based on hepatocellular carcinoma. PLoS One 2016;11:e0153882.

51. Rogacki K, Kasprzak A, Stępiński A. Alterations of Wnt/B-catenin signaling pathway in hepatocellular carcinomas associated with hepatitis C virus. Pol J Pathol 2015;66:9-21.

52. Wang W, Pan Q, Fuhler GM, Smits R, Peppelenbosch MP. Action and function of Wnt/ $\beta$-catenin signaling in the progression from chronic hepatitis C to hepato- cellular carcinoma. J Gastroenterol 2017;52:419-31.

53. Jiang XH, Xie YT, Cai YP, Ren J, Ma T. Effects of hepatitis C virus core protein and nonstructural protein $4 \mathrm{~B}$ on the Wnt $/ \beta$-catenin pathway. BMC Microbiol 2017;17:124.

54. Liu J, Ding X, Tang J, Cao Y, Hu P, Zhou F, Shan X, Cai X, Chen Q, Ling N, Zhang B, Bi Y, Chen K, Ren H, Huang A, He TC, Tang N. Enhancement of canonical Wnt/ $\beta$-catenin signaling activity by HCV core protein promotes cell growth of hepatocellular carcinoma cells. PLoS One 2011;6:e27496.

55. Liu J, Wang Z, Tang J, Tang R, Shan X, Zhang W, Chen Q, Zhou F, Chen K, Huang A, Tang N. Hepatitis C virus core protein activates Wnt/ $\beta$-catenin signaling through multiple regulation of upstream molecules in the SMMC-7721 cell line. Arch Virol 2011;156:1013-23.

56. Kasprzak A, Rogacki K, Adamek A, Sterzyńska K, Przybyszewska W, Seraszek-Jaros A, Helak-Łapaj C, Pyda P. Tissue expression of $\beta$-catenin and E- and N-cadherins in chronic hepatitis C and hepatocellular carcinoma. Arch Med Sci 2017;13:1269-80.

57. Umer M, Qureshi SA, Hashmi ZY, Raza A, Ahmad J, Rahman M, Iqbal M. Promoter hypermethylation of Wnt pathway inhibitors in hepatitis C virus - induced multistep hepatocarcinogenesis. Virol J 2014;11:117.

58. Liu Y, El-Serag HB, Jiao L, Lee J, Moore D, Franco LM, Tavakoli-Tabasi S, Tsavachidis S, Kuzniarek J, Ramsey DJ, White DL. WNT signaling pathway gene polymorphisms and risk of hepatic fibrosis and inflammation in HCV-infected patients. PLoS One 2013;8:e84407.

59. Quan H, Zhou F, Nie D, Chen Q, Cai X, Shan X, Zhou Z, Chen K, Huang A, Li S, Tang N. Hepatitis C virus core protein epigenetically silences SFRP1 and enhances HCC aggressiveness by inducing epithelial-mesenchymal transition. Oncogene 2014;33:2826-35.

60. Ueda T, Honda M, Horimoto K, Aburatani S, Saito S, Yamashita T, Sakai Y, Nakamura M, Takatori H, Sunagozaka H, Kaneko S. Gene expression profiling of hepatitis B- and hepatitis C-related hepatocellular carcinoma using graphical Gaussian modeling. Genomics 2013;101:238-48.

61. Lu C, He Y, Duan J, Yang Y, Zhong C, Zhang J, Liao W, Huang X, Zhu R, Li M. Expression of Wnt3a in hepatocellular carcinoma and its effects on cell cycle and metastasis. Int J Oncol 2017;51:1135-45.

62. Zhang C, Li C, Chen X, Zhou Y, Yin B, Ni R, Zhang Y, Liu J. Overexpression of dishevelled 2 is involved in tumor metastasis and is associated with poor prognosis in hepatocellular carcinoma. Clin Transl Oncol 2017;19:1507-17.

63. Sakabe T, Azumi J, Umekita Y, Toriguchi K, Hatano E, Hirooka Y, Shiota G. Expression of cancer stem cell-associated DKK1 mRNA serves as prognostic marker for hepatocellular carcinoma. Anticancer Res 2017;37:4881-8.

64. Davaadorj M, Imura S, Saito YU, Morine Y, Ikemoto T, Yamada S, Takasu C, Hiroki T, Yoshikawa M, Shimada M. Loss of SFRP1 expression is associated with poor prognosis in hepatocellular carcinoma. Anticancer Res 2016;36:659-64.

65. Wang L, Yao M, Fang M, Zheng WJ, Dong ZZ, Pan LH, Zhang HJ, Yao DF. Expression of hepatic Wnt5a and its cliniopathological features in patients with hepatocellular carcinoma. Hepatobiliary Pancreat Dis Int 2018;17:227-32.

66. Wang L, Pan LH, Yao M, Zheng WJ, Fang M, Qiu LW, Dong ZZ, Yao DF. Clinical values of Wnt3a as a novel biomarker in diagnosis and prognosis of hepatocellular carcinoma. Zhonghua Yi Xue Za Zhi 2016;96:3554-8. (in Chinese)

67. Naboulsi W, Megger DA, Bracht T, Kohl M, Turewicz M, Eisenacher M, Voss DM, Schlaak JF, Hoffmann AC, Weber F, Baba HA, Meyer HE, Sitek B. Quantitative tissue proteomics analysis reveals versican as potential biomarker for early-stage hepatocellular carcinoma. J Proteome Res 2016;15:38-47.

68. Su YH, Lin SY, Song W, Jain S. DNA markers in molecular diagnostics for hepatocellular carcinoma. Expert Rev Mol Diagn 
2014;14:803-17.

69. Zheng WJ, Yao M, Qian Q, Sai WL, Qiu LW, Yang JL, Wu W, Dong ZZ, Yao DF. Oncogenic secretory clusterin in hepatocellular carcinoma: Expression at early staging and emerging molecular target. Oncotarget 2017;8:52321-32.

70. Dong ZZ, Zhu XD, Li Z, Mao YG, Chai YL, Yao DF, Sun HC, Zhu JY, Ma KS. Advances in basic and clinical research on hepatocellular carcinoma in 2016. Zhonghua Gan Zang Bing Za Zhi 2017;25:85-93. (in Chinese)

71. Yang Y, Yao M, Fang M, Zheng WJ, Dong ZZ, Yao DF. Molecular markers for the monitoring of malignant transformation of hepatocytes and early diagnosis of liver cancer. Zhonghua Gan Zang Bing Za Zhi 2017;25:325-8. (in Chinese)

72. Yao DF, Jiang DR, Huang ZW, Lu JX, Tao QY, Yu ZJ, Meng X. Abnormal expressiom of hepatoma specific $\gamma$-glutamyl transferase and alteration of $\gamma$-glutamyl transferase gene methylation status in patients with hepatocellular carcinoma. Cancer 2000;88:761-9.

73. Yao M, Yao DF, Bian YZ, Wu W, Yan XD, Yu DD, Qiu LW, Yang JL, Zhang HJ, Sai WL, Chen J. Values of circulating GPC-3 mRNA and alpha-fetoprotein in detecting patients with hepatocellular carcinoma. Hepatobiliary Pancreat Dis Int 2013;12:171-9.

74. Erdal H, Gül Utku Ö, Karatay E, Çelik B, Elbeg Ş, Doğan İ. Combination of DKK1 and AFP improves diagnostic accuracy of hepatocellular carcinoma compared with either marker alone. Turk J Gastroenterol 2016;27:375-81.

75. Guo Y, Wang J, Zhang L, Shen S, Guo R, Yang Y, Chen W, Wang Y, Chen G, Shuai X. Theranostical nanosystem-mediated identification of an oncogene and highly effective therapy in hepatocellular carcinoma. Hepatology 2016;63:1240-55.

76. Witt-Kehati D, Fridkin A, Alaluf MB, Zemel R, Shlomai A. Inhibition of pMAPK14 overcomes resistance to sorafenib in hepatoma cells with hepatitis B virus. Transl Oncol 2018;11:511-7.

77. Shang $\mathrm{S}$, Hua F, Hu ZW. The regulation of $\beta$-catenin activity and function in cancer: therapeutic opportunities. Oncotarget 2017;8:33972-89.

78. Liu J, Pan S, Hsieh MH, Ng N, Sun F, Wang T, Kasibhatla S, Schuller AG, Li AG, Cheng D, Li J, Tompkins C, Pferdekamper A, Steffy A, Cheng J, Kowal C, Phung V, Guo G, Wang Y, Graham MP, Flynn S, Brenner JC, Li C, Villarroel MC, Schultz PG, Wu X, McNamara P, Sellers WR, Petruzzelli L, Boral AL, Seidel HM, McLaughlin ME, Che J, Carey TE, Vanasse G, Harris JL. Targeting Wnt-driven cancer through the inhibition of Porcupine by LGK974. Proc Natl Acad Sci U S A 2013;110:20224-9.

79. Tuynman JB, Vermeulen L, Boon EM, Kemper K, Zwinderman AH, Peppelenbosch MP, Richel DJ. Cyclooxygenase-2 inhibition inhibits c-Met kinase activity and Wnt activity in colon cancer. Cancer Res 2008;68:1213-20.

80. Su Y, Simmen RC. Soy isoflavone genistein upregulates epithelial adhesion molecule E-cadherin expression and attenuates beta-catenin signaling in mammary epithelial cells. Carcinogenesis 2009;30:331-9.

81. Sebio A, Kahn M, Lenz HJ. The potential of targeting Wnt/beta-catenin in colon cancer. Expert Opin Ther Targets 2014;18:611-5.

82. Takada K, Zhu D, Bird GH, Sukhdeo K, Zhao JJ, Mani M, Lemieux M, Carrasco DE, Ryan J, Horst D, Fulciniti M, Munshi NC, Xu W, Kung AL, Shivdasani RA, Walensky LD, Carrasco DR. Targeted disruption of the BCL9/beta-catenin complex inhibits oncogenic Wnt signaling. Sci Transl Med 2012;4:148ra117.

83. Yu D, Dong Z, Yao M, Wu W, Yan M, Yan X, Qiu L, Chen J, Sai W, Yao D. Targeted glypican-3 gene transcription inhibited the proliferation of human hepatoma cells by specific short hairpin RNA.Tumour Biol 2013;34:661-8.

84. Jin Y, Wang J, Han J, Luo D, Sun Z. MiR-122 inhibits epithelial-mesenchymal transition in hepatocellular carcinoma by targeting Snail1 and Snail2 and suppressing WNT/ß-cadherin signaling pathway. Exp Cell Res 2017;360:210-7.

85. Kim SS, Cho HJ, Lee HY, Park JH, Noh CK, Shin SJ, Lee KM, Yoo BM, Lee KJ, Cho SW, Cheong JY. Genetic polymorphisms in the $\mathrm{Wnt} / \beta$-catenin pathway genes as predictors of tumor development and survival in patients with hepatitis B virus-associated hepatocellular carcinoma. Clin Biochem 2016;49:792- 801.

86. Lin HH, Feng WC, Lu LC, Shao YY, Hsu CH, Cheng AL. Inhibition of the Wnt/ $\beta$-catenin signaling pathway improves the anti-tumor effects of sorafenib against hepatocellular carcinoma. Cancer Lett 2016;381:58-66.

87. Shen YN, He HG, Shi Y, Cao J, Yuan JY, Wang ZC, Shi CF, Zhu N, Wei YP, Liu F, Huang JL, Yang GS, Lu JH. Krüppel-like factor 8 promotes cancer stem cell-like traits in hepatocellular carcinoma through Wnt/ß-catenin signaling. Mol Carcinog 2017;56:751-60.

88. Shibata T, Arai Y, Totoki Y. Molecular genomic landscapes of hepatobiliary cancer. Cancer Sci 2018;109:1282-91. 